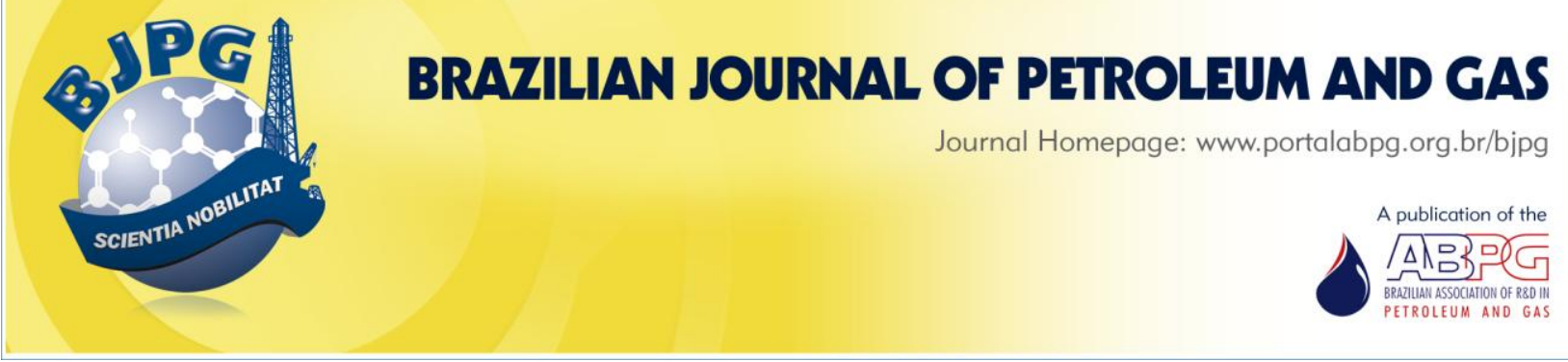

\title{
RECOVERY OF USED LUBRICANT OILS THROUGH ADSORPTION OF RESIDUES ON SOLID SURFACES
}

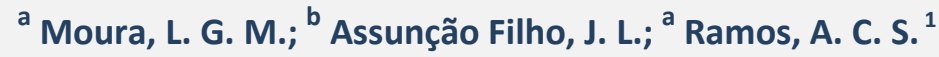 \\ a Departamento de Tecnologia Química, Centro de Ciências Exatas e Tecnologia, Universidade Federal do Maranhão \\ b Departamento de Pós-Graduação em Química, Centro de Ciências Exatas e Tecnologia, Universidade Federal do Maranhão
}

\begin{abstract}
Waste lubricant oils are products that undergo degradation due to their use, yielding substances that are potentially carcinogenic, such as PAHs (polycyclic aromatic hydrocarbons), which renders them improper. In this work, a sequence of physical steps was investigated focusing on the adsorption on solids for PAHs removal. Adsorption isotherms were constructed considering the PAHs concentration capacity presented by different solids, with activated carbon as the most efficient adsorbent in the removal of PAHs. At the end of the process it was possible to reestablish the main properties of the base oil, and to propose a methodology for the recovery of the base oil, comprising solvent extraction, adsorption on solid surfaces and solvent distillation, making it adequate to be reintroduced into the production chain.
\end{abstract}

\section{KEYWORDS}

lubricant oils; polycyclic aromatic hydrocarbons; adsorption; solvent extraction; recycling

\footnotetext{
${ }^{1}$ To whom all correspondence should be addressed.

Address: Avenida dos Portugueses s/n - Campus Universitário do Bacanga / CEP 65.040-080 / São Luís - Maranhão - Brasil Telephone: +55-98-3301-8266 / Fax: +55-98-3301-8245 | e-mail: ramosacs@gmail.com doi:10.5419/bjpg2010-0010
} 


\section{INTRODUCTION}

Lubricant base oils are mixtures that are essentially formed by the fractions of petroleum which are distilled between $300{ }^{\circ} \mathrm{C}$ and $400{ }^{\circ} \mathrm{C}$ under atmospheric pressure, containing saturate hydrocarbons and lower amounts of aromatic and naphthenic compounds (Serrano et al., 2003; Shishkin, 2006).

In order to obtain commercial lubricant oils, base oils are mixed with additives which particularize them or enhance some of their characteristics. The role of these products is to minimize wearing caused by physical friction, by separating moving surfaces with the formation of a thin resistant layer. This gives them a wide range of applications on a variety of mechanical equipments, namely industrial, automotive, marine, railroads and hydraulic systems (Al-Ghouti and Al-Atoum, 2007; Ramasamy and T-Raissi, 2007; Rauckyte and Hargreaves, 2006).

Lubricant oils are classified within the few petroleum derivatives which are just partially consumed during their use, with a limited usage life term specified by the makers. After this period of time, they become more prone to thermal degradation and oxidation, thereby impairing their use due to loss of lubricant ability, and requiring replacement (Hamad et al., 2005; Raadnui and Kleesuwan, 2005).

Used oils from mineral sources are not biodegradable and contain materials produced in the degradation of base oils, such as polycyclic aromatic hydrocarbons (PAHs) with high viscosity; oxygen compounds (organic acids, ketones); resins and lacs; non-consumed additives; waste metals from motors and lubricated machines, such as iron, lead, chromium, barium and cadmium; and other contaminants like water, non-burned fuel, dust and various impurities which present risks to the environment and to the public health (Rauckyte and Hargreaves, 2006; Uçar et al., 2005). Oxidation is the main degradation process, but due to the natural complexity of these systems, the formation of deposits and aromatic structures of high molecular weight is still an elusive issue (Santos et al., 2004).

Until now, it is well known that petroleum is a limited non-renewable resource, hence processes that allow for the prolongation of the oils usage life term may be highly interesting for commercial and environmental purposes.

In Brazil, the industrial operation which is used to obtain base oils is called re-refining, aimed at removing contaminants, degraded products and additives from used oils in order to reestablish the base lubricant oil characteristics, according to specifications of the Brazilian Environmental Council (Conselho Nacional do Meio Ambiente, CONAMA). The Brazilian Agency of Petroleum, Natural Gas and Biofuels (Agência Nacional de Petróleo, Gás Natural e Biocombustíveis, ANP) is the Brazilian institution in charge of the inspection, collection and destination of the used lubricant oils. According to the CONAMA resolution \# 9, of August 31, 1993, it constitutes crime to give a different destiny to used oils such as discharge in natural areas, commercialization, burning and transportation other than the regulated re-refining (CONAMA, 1993). Re-refined oils return to the market, creating jobs, avoiding expenses and minimizing environmental pollution.

Alternatives to industrial re-refining processes are very valuable to obtain a product (base oil) which, by proving to be more efficient and cheaper than the conventional ones, could be reintroduced in the production chain (Al-Ghouti and Al-Atoum, 2007; Gómez-Rico et al., 2003; Sarrade et al., 2001).

Some of the particulate materials found in the waste oils can be removed by classical unit operations, such as filtering and centrifugation; however, some other undesirable substances remain soluble and may occur in high concentrations, thus decreasing the re-refining efficiency. Recent studies have focused on particle removal by solvent extraction as an essential step in the global recovery process of used oils. It can be noticed, however, that in this case it is still necessary to conduct the re-refining in order to obtain the base oil (Espada et al., 2008; Grieken et al., 2008; Hamad et al., 2005).

Polycyclic aromatic hydrocarbons (PAHs) are among the main soluble contaminants. Ramos et al. (2001) evaluated the adsorption of petroleum polyaromatic fractions, called asphaltenes and resins, on the surface of different solids. Results indicated that these fractions tend to concentrate on the surface of different solids forming 
multilayers. The interaction between the molecules and the surface varies according to the adsorbent chemical nature. Other studies (Mousavi-Dehghani et al., 2004; Priyanto et al., 2001; Rincón et al., 2007) also showed that these petroleum fractions exhibit interfacial activity in aromatic solvents, which may explain its tendency to adsorption. Some oxide byproducts of used oils, such as the PAHs, are chemically similar to the petroleum heavy fractions, which makes the adsorption a potential step to the removal of residues from used lubricant oils (Araújo et al., 2008; Shaw, 1975).

In this work a sequence of physical steps was designed to obtain base oils from used lubricant oils, focusing on the removal of PAHs from used oils through adsorption on solids of different nature, such as activated carbon, rice husk, silica$\mathrm{NH}_{2}$, residues from acetylene synthesis, babaçu epicarp and benzoin gum.

\section{MATERIALS AND METHODS}

\subsection{Materials}

The waste lubricant oil was collected in the city of São Luís, in the State of Maranhão (Brazil).

The solvents n-pentane (Carlo Erba, 99.5\%), nhexane (Carlo Erba, 99.6\%), n-heptane (Carlo Erba, 99.75\%), toluene (Carlo Erba, 99.5\%; F. Maia, 99.5\%), ethanol (Merk, 99.8\%; Isofar, 99.5\%), propan-2-ol (Reagen, 99.5\%; Vetec, 99.5\%), butan1-ol (Grupo Química, 99.5\%; Reagen, 99.4\%) and terc-butanol (Vetec, 99.0\%) were used to study the solubility of the waste lubricant oils.

The adsorbents activated carbon, silica-gel, rice husk, silica- $\mathrm{NH}_{2}$, residues from acetylene synthesis, babaçu epicarp and benzoin gum were used in the adsorption tests. Activated carbon, silica gel and alumina were also used in acidity determinations.

\subsection{Preparation of a PAHs-concentrated solid from the waste lubricant oil}

Oil and butan-1-ol were mixed to a 1:2 ratio, followed by 30 min stirring and $1 \mathrm{~h}$ centrifugation, forming a biphasic system. The extract phase was discharged and the remaining refined phase was transferred to a Whatman \# 42 filter paper, and then to a soxhlet extractor in which the organic material was extracted by continuous reflux with toluene. Toluene was then distilled and evaporated until a pastry material was obtained, which was then transferred to a new filter paper and washed in the soxhlet with pentane in order to extract the residual oil. This practice was continued until the refluxed solvent became clean. The pentanecontaining solution was replaced with pure toluene in order to extract the remaining material from the filter paper. The obtained solution was submitted to distillation and evaporation so as to remove the toluene, yielding a solid which was placed in a dessicator for $24 \mathrm{~h}$, before weighing.

\subsection{Characterization of the PAHs- concentrated solid (reference material)}

The solids obtained according to the procedure described in section 2.2 were mixed with spectroscopic potassium bromide $(\mathrm{KBr})$ at a 1:10 ratio, followed by homogenization into a porcelain melting pot and compression to 10 ton in order to obtain a pastille, at $27 \pm 1{ }^{\circ} \mathrm{C}$. The pastille was then placed in a Nicolet Nexus 470 FT-IR spectrophotometer and the vibration spectra were acquired.

\subsection{Building of calibration curves for PAHs quantification}

Solutions of the solid (obtained as described in section 2.3) were prepared in toluene at different concentrations, attaining their respective scanning spectrum in the UV-visible region. A Varian Cary50 Spectrophotometer with a $1 \mathrm{~cm}$ glass cell was used to acquire absorbance curves as a function of the concentration. A similar procedure was employed to obtain the absorbance curves as a function of the PAHs concentration in the systems with mixtures of oil-alcohol (ethanol, propan-2-ol or butan-1-ol).

\subsection{Adsorption isotherms}

Adsorption isotherms were constructed starting with a fixed mass of adsorbent by varying the PAHs concentrations in ethanol, propan-2-ol or butan-1ol. The solution/solid contact time was always higher than the minimum time estimated in adsorption kinetics studies carried out in this work. 


\subsection{Base oil recovery}

Oil and alcohol (ethanol and propan-2-ol) were mixed at a 1:2 ratio, stirred for $30 \mathrm{~min}$ and centrifuged for $1 \mathrm{~h}$, forming a biphasic system. The supernatant was put in contact with the adsorbent and, after equilibrium was reached, it was collected and subjected to acidity tests (ASTM D3339-95) by means of an A E536 Netron-Herisan Potentiograph with a Netron 655 Dosimat automatic burette. Lubricant oils were recovered from the supernatant by means of fractionated distillation.

\subsection{Determination of metals in the oil samples}

The amounts of $\mathrm{Fe}, \mathrm{Pb}, \mathrm{Zn}$ and $\mathrm{Cu}$ in the recovered oil samples were determined by means of atomic emission spectrometry according to the procedure established by the ASTM D6595 method.

\section{RESULTS AND DISCUSSION}

\subsection{Preliminary remarks}

Samples of the lubricant oils were employed as received. Digital images of the novel and used oils, obtained through an Olympus BX 51/BX 52 Optical Microscope, are shown in Figure 1. In Figure 1a it can be observed that the sample is completely clean, contrasting with Figure $1 \mathrm{~b}$, which depicts a sample of used oil with much particulate material formed by oil degradation and contamination. The average size of the suspended particles of the waste oil was determined as $1.0 \pm 0.1 \mu \mathrm{m}$ and no evidence of emulsified water was identified.

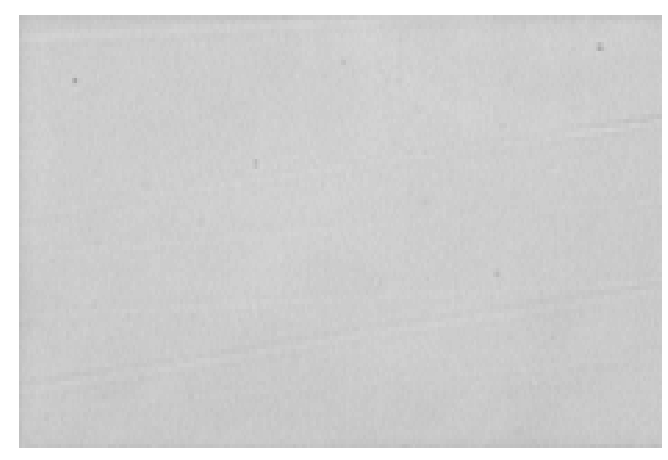

(1a)
Centrifugation of the waste oil samples (at a maximum $4000 \mathrm{rpm}$ in a Janetzki T32c centrifuge) practically did not cause any reduction in the amount of the suspended particulate material, as observed with the optical microscope. Hence, two strategies were adopted. Firstly, pentane and/or heptane was added to the waste oil. These solvents act as flocculants of heavy aromatic oil fractions. The objective of this procedure was to increase particles size, so that a positive response is provoked in the natural sedimentation or in the centrifugal field. In this study, a significant increase in particle size was noticed, but it was not possible to remove the particulate material from the waste oil, even when centrifuged. The second strategy was the addition of toluene, a renowned solvent for crude oil and its derivatives, to reduce the viscosity of the medium. The addition of toluene up to $50 \%$ in volume did not yield the desired suspension separation. In particular, a large amount of toluene would render any industrial process economically unfeasible.

Facing the first negative test results, the next step was to add substances that are partially soluble in the waste oil, in order to generate a biphasic system and estimate their efficiency in the recovery of base oil from one of the phases. In the estimated proportions, the systems with lubricant oil added with alcohol (ethanol, propan-2-ol, tercbutanol and butan-1-ol) were soluble due to the lack of emulsions when checked through the optical microscope.

The formation of biphasic systems by adding alcohol confirmed the possibility to develop a procedure based on liquid-liquid extraction. Since terc-butanol and butan-1-ol presented very close results, butan-1-ol was chosen for the subsequent

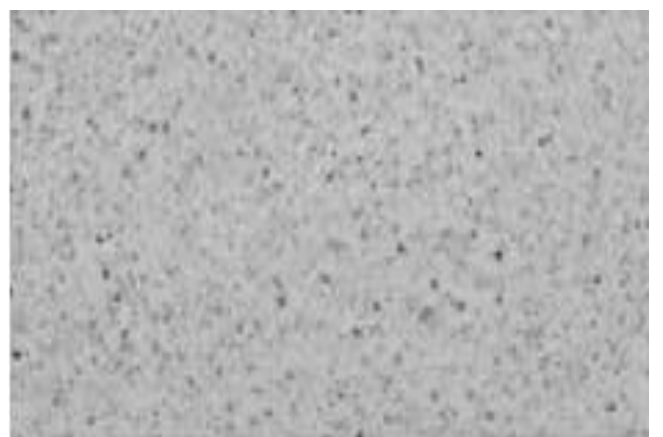

(1b)

Figure 1. Digital images of the new (a) and waste (b) lubricant oils (400 times magnification). 
experiments, particularly because it is less expensive. In these systems, the suspended particles in the waste oil were concentrated in the lower phase (lees), whilst the bulk of the base lubricant oil was concentrated in the upper, supernatant phase. Supernatants of used oil mixed with ethanol, propan-2-ol and butan-1-ol were used to evaluate the adsorption of soluble polyaromatic residues on different solids. In order to quantify the transfer of the PAHs from the supernatants to the solid surfaces, it was initially necessary to establish a method that allowed the monitoring of PAHs, and for that purpose the technique used was molecular adsorption spectrophotometry in the UV-visible region.

\subsection{PAHs characterization and quantification}

The particulate material (phase containing lees) was submitted to a treatment in order to obtain a solid with high concentration of PAHs, as explained in Section 2.2.

It is useful to note that, in the characterization of the reference sample by the FT-IR technique, it was not possible to get a fair homogenization of the reference material with $\mathrm{KBr}$ to acquire the vibration spectra. This probably caused the transmittance interval to remain unfit within the desired range of values (30 to $70 \%$ ) (Silvestein and Webster, 1997). Nevertheless, this result did not impair the PAHs qualitative analysis.

Analysis of Figure 2 allowed the identification of some characteristic bands of systems containing polyaromatic hydrocarbons, typically in three spectral regions and in accordance with specific references (Silvestein and Webster, 1997).

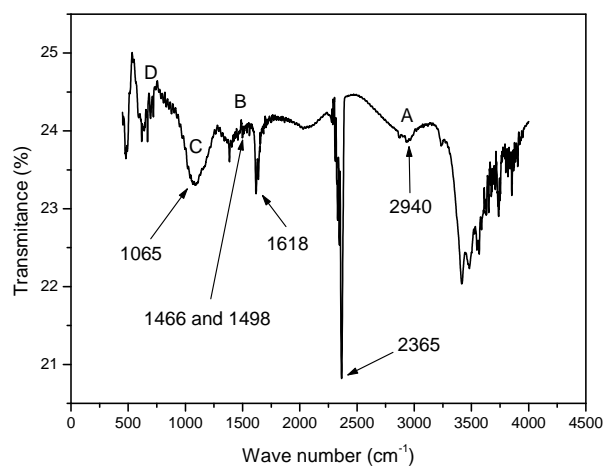

Figure 2. Infrared vibration spectrum (FT-IR) of the reference sample after washing with $n$-pentane.

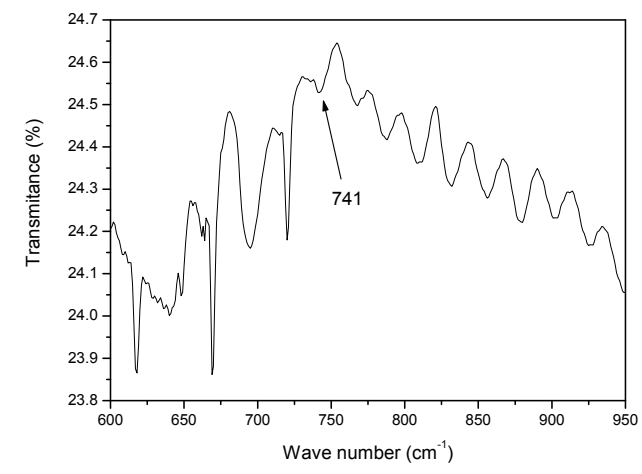

Figure 3. Infrared vibration spectrum (FT-IR) of the reference sample after washing with $n$-pentane.

However, it is noticeable that, when dealing with a sample with high polidispersity, strong dependence with the medium (surroundings) can occur, as shown by the shape and distribution of the bands. The first band is attributed to aromatic $\mathrm{C}-\mathrm{H}$ axial deformation vibrations, which occur between 3000 and $3100 \mathrm{~cm}^{-1}$; methyl axial deformation can be detected at 2965, 2940, 2918 and $2875 \mathrm{~cm}^{-1}$, comprising the " $\mathrm{A}$ " region in Figure 2.

The second important band in the characterization of PAHs is formed by a set of peaks between 1500 and $1630 \mathrm{~cm}^{-1}$ related to the $\mathrm{C}=\mathrm{C}$ axial deformation of the aromatic ring (the " $\mathrm{B}$ " region in Figure 2 ). There is also a region between 1000 and $1300 \mathrm{~cm}^{-1}$ ("C $\mathrm{C}^{\prime}$ ) where a wide band can be observed due to $\mathrm{C}-\mathrm{H}$ angular deformation in the plane. Finally, the " $D$ " region, from 675 to $900 \mathrm{~cm}^{-1}$, refers to the angular deformation of the $\mathrm{C}-\mathrm{H}$ bound planes of the aromatic ring. In order to allow for better peak interpretation, this region can be seen in a separate graph (Figure 3 ).

Taking into account that the reference solid is formed by a polydisperse sample, it was also decided to investigate the FT-IR spectrum after washing with hexane. This was also justified by the fact that hexane is a substance typically used in the extraction of oils, especially those of vegetable origin. The FT-IR spectrum of the reference sample after washing with hexane is shown in Figure 4. The experiment was conducted in similar conditions to those of the reference sample after washing with pentane.

In Figure 4, a similarity can be verified between the FT-IR spectra of both reference samples by the occurrence of the same bands that characterize 
aromatic and polyaromatic compounds, although this is more prominent in Figure 4. Since the purpose of this work is to use the samples as parameters to evaluate the PAHs transfer in the process of adsorption on solid surfaces, these results were considered reasonably qualitative.

Scanning spectra of the PAHs-rich solid solubilized in toluene (concentrations of $0.03 ; 0.10$; 0.25; e $0.50 \mathrm{~g} \cdot \mathrm{L}^{-1}$ ) were obtained in the UV-visible region at room temperature $\left(27 \pm 1^{\circ} \mathrm{C}\right)$. In order to better view the region of interest, the spectra depicted in Figure 5 shows only the bands between 320 and $720 \mathrm{~nm}$. Lack of adsorption peaks was observed on the curves, a typical behavior of polydisperse systems.

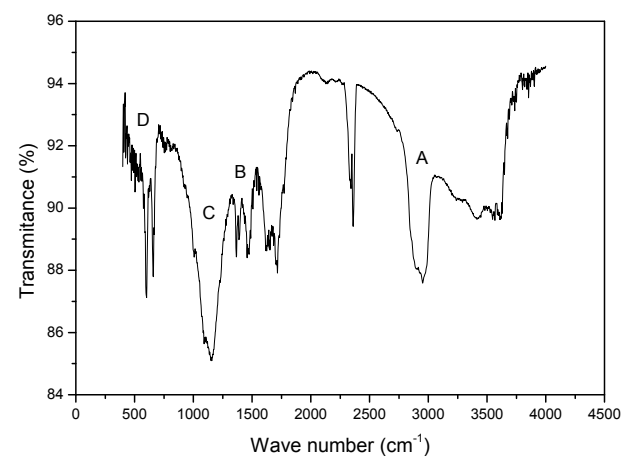

Figure 4. Infrared vibration spectrum (FT-IR) of the reference sample after washing with $n$-hexane.

The 350 and $400 \mathrm{~nm}$ wavelengths were selected to study the PAHs in the supernatant, mainly based upon similar studies using asphaltene and resin solutions (crude oil polyaromatic fractions) in aromatic solvents (Chang and Fogler 1993; Ramos et al., 2001).

Two calibration curves were built, at 350 and $400 \mathrm{~nm}$, proceeding with concentrations at which the maximum signal of 2 adsorption units was obtained, so as to minimize deviation from ideality, according to information available in the literature (Chang and Fogler 1993; Ramos et al., 2001). Both curves exhibited similar behavior, revealing good linearity between adsorption and PAHs concentration. Improved linearity was obtained at $350 \mathrm{~nm}$; therefore, this wavelength was selected in this work to determine the amount of PAHs in toluene, since it produced a correlation coefficient value that was closest to unity. However, if the accuracy in the concentration measurement is considered in both cases, the coefficients are equally close to 1.0 .

The curve of absorbance (A) as a function of concentration $(C)$, given by the equation $A=$ $3.42742 \cdot C-0.00568$, was used to determine the amount of PAHs in the supernatant phases of other systems. To estimate the correlation between the PAHs concentrations in toluene and the concentrations in the other systems, PAHs calibration curves in alcohols were built using the respective supernatants.

It was proved that the scanning spectra of the PAHs in alcohols did not present defined peaks in the visible region, with behavior similar to the one observed in the toluene curves. The readings were recorded considering adsorption levels lower than 2 , in good agreement with the Lambert-Beer law. In Table 1 the equations originated from the calibrations curves of the PAHs in the evaluated alcohols are presented.

From Table 1, it was possible to extract the values of the molar absortivity: 0.46463 for ethanol, 0.859460 for propan-2-ol and 1.08387 for butan-1-ol. These values differ from one another and also from the one found for toluene (3.42742), indicating the effects of the medium on the PAHs solubility. Therefore, it is not possible to establish a

Table 1. Equations from the calibration curves of PAHs in alcohols (ethanol, propan-2-ol and butan-1-ol) at $27 \pm 1{ }^{\circ} \mathrm{C}$.

\begin{tabular}{ccc}
\hline Solvent & Equation & Correlation Coefficient $\left(\mathbf{R}^{2}\right)$ \\
\hline Ethanol & $\mathrm{A}=0.46463 \cdot \mathrm{C}+0.0241$ & 0.99911 \\
Propan-2-ol & $\mathrm{A}=0.85946 \cdot \mathrm{C}+0.1565$ & 0.99997 \\
Butan-1-ol & $\mathrm{A}=1.08387 \cdot \mathrm{C}+0.0184$ & 0.99980 \\
\hline
\end{tabular}


precise correlation for the determination of the PAHs concentration; however a relationship between the absorbance and concentration can be applied to quantify the variation in the PAHs mass for all systems.

\subsection{Adsorption isotherms}

After defining the methodology for monitoring the PAHs concentration in the supernatants, the next step was to estimate the different solids' adsorption capacity (activated carbon, rice husk, silica- $\mathrm{NH}_{2}$, residues from acetylene synthesis, babaçu epicarp and benzoin gum) with respect to PAHs. To do so, first a study was performed on the adsorption kinetics in each system aiming at the determination of the equilibrium time. The experiments were conducted starting from three initial concentrations. The most concentrated system was prepared at a 2:1 ratio of solvent and waste oil, in that order, without dilution. The plots in Figures 5 and 7 to 11 refer only to solutions with higher concentration for each solvent, since the remaining solutions with other concentrations presented the same behavior.

Figure 5 shows the adsorption kinetics for the supernatants of the oil-alcohol systems on activated carbon. The initial concentration decreases slowly until reaching equilibrium in about $72 \mathrm{~h}$. This result, in principle, is irrespective of the nature of the solvent. This balancing time was also found in the studies by Assunção Filho (2004) for equivalent systems, which reinforces the validity of the results obtained here.

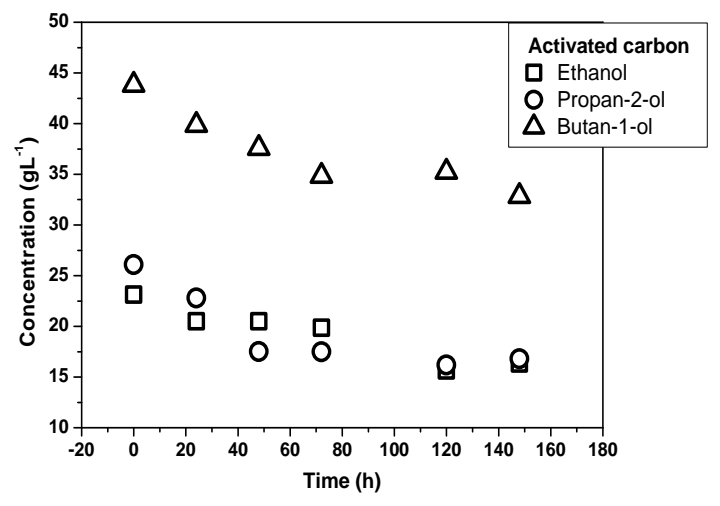

Figure 5. Supernatant concentrations of oil/ethanol, oil/propan-2-ol and oil/butan-1-ol systems as a function of adsorption time over activated carbon at $350 \mathrm{~nm}$ and $28 \pm 1^{\circ} \mathrm{C}$.
The fact that the initial PAHs concentration is different for each system proves that the base oil solubility depends on the nature of the alcohol. Taking into account that the volume of the phases differed according to the sequence butan-1-ol > propan-2-ol > ethanol, it was possible to conclude that, in this case, the best solvent to extract base oil starting from used oil is butan-1-ol, followed by propan-2-ol and ethanol. The period of $72 \mathrm{~h}$ suggests slow transference kinetics for the PAHs adsorption process over activated carbon, and the same period of time was measured for other solids.

Figure 6 presents the adsorption isotherms for the activated carbon system in different solvents. An increase in the surface concentration occurs with increasing equilibrium concentration. The isotherms behavior suggests enhanced adsorption in the systems with ethanol, followed by propan-2ol and butan-1-ol. That result is in good agreement with the higher PAHs solubility in the butan-1-ol and with studies that indicate a more effective adsorption of that sort of compounds, when using rather polar solvents (Dubey and Waxman, 1991; Jiao et al., 2007). Moreover, this points out at a potential technological application of this solid to remove part of the PAHs from used lubricant oils. The isotherms reported by Assunção Filho (2004) clearly suggest an L2-type physical adsorption (Myers, 1999), corresponding to a multilayer formation process that is, in principle, slightly different from the ones presented in this article, which show a less evident tendency. In this study, within the concentration range assessed, the results indicate that there is still a large area available for adsorption and, therefore, solids saturation did not occur.

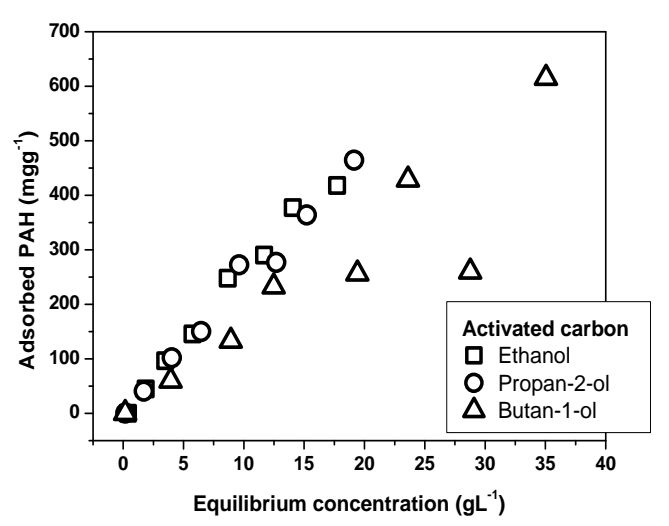

Figure 6. Adsorption isotherms of PAHs over activated carbon in oil/ethanol, oil/propan-2-ol and oil/butan-1-ol systems at $28 \pm 1{ }^{\circ} \mathrm{C}$. 


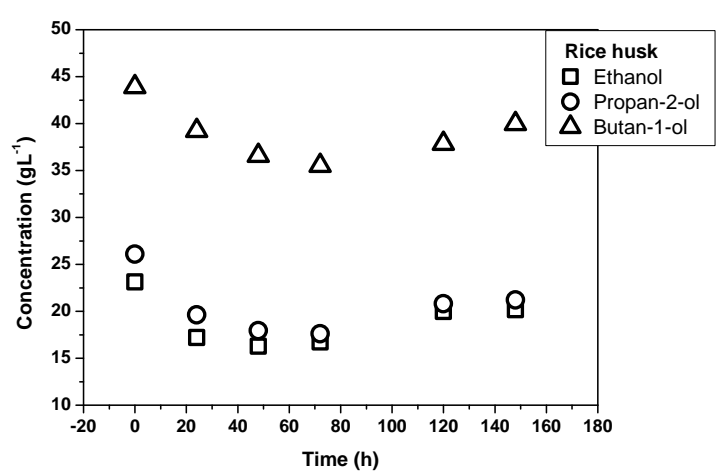

Figure 7. Supernatant concentrations of oil/ethanol, oil/propan-2-ol and oil/butan-1-ol systems as a function of adsorption time over rice husk at $28 \pm 1^{\circ} \mathrm{C}$

The industrial application of this solvent can be extended for the removal of polyaromatic hydrocarbons in crude oil fluids, taking into account that there have been similar results reported on asphaltene adsorption in toluene over activated carbon (Ramos et al., 2001). This solid is obtained from organic materials (such as wood powder, vegetal carbon, crude oil coke and bitumen) and the activation is a physical modification that augments its surface area by removing natural hydrocarbons, which can confirm the affinity derived from chemical similarity with the adsorbates. Moreover, physical adsorption is principally based upon van der Waals forces and weak bonds emerged from the formation of a dipole momentum in the particles due to electron dislocations. The surface of activated carbon is plenty of free charges, generated mainly during the activation process, a feature that enhances the adsorption effects with aromatic compounds, which are scarcely polar but present resonance that turns them more susceptible to formation of dipole momentum. In view of this, the higher efficacy of activated carbon in PAHs adsorption can be justified mainly because of its nature (Ahmedna et al., 2000; László et al., 1997; Shreve and Brink Jr., 1997).

Adsorption studies were carried out with other solids, such as rice husk, which has some characteristics that render it as potential PAHs adsorbent, namely the occurrence of hydroxyl functional groups on its surface (Ahmedna et al., 2000; László et al., 1997). This is also the case with solid chitosan, which has been reported as a good candidate to concentrate PAHs (Assunção Filho, 2004).
Figure 7 presents a study of PAHs adsorption kinetics on rice husk, and the results found are, in principle, similar to the ones presented by activated carbon. Again the observed sequence of enhanced base oil extraction was butan-1-ol > propan-2-ol > ethanol. A tendency to reach the equilibrium concentration around $48 \mathrm{~h}$ was observed, however, from which point there is a further increase in the PAHs concentration in the supernatant. Since each experiment in this work was carried out at least three times, such behavior is not a consequence of an analytical error, but is probably due to PAHs desorption as a result of modifications on the surface of rice husk by reaction with solvent or changes in the medium acidity, as confirmed by further tests. Ajmal et al. (2003) used this solid for metal adsorption, and described the use of acids in the desorption step, which can be based not only in the solubilization of those metals, but also in a solid surface change and in the inhibition of active sites. This result represents a negative aspect for the use of rice husk as PAHs adsorbent and, in this work, such aspect was considered to interrupt its investigation.

Figures 8 through 11 present the results of kinetics studies on PAHs adsorption over different adsorbents, namely modified silica, the soot formed during acetylene synthesis, babaçu epicarp and benzoin gum. All the experiments were done in triplicate and the results were very similar. For this reason, the graphs were constructed employing the average value of each determination.

The tested silica was modified by doping with nitrogen compounds (Farias and Airoldi, 2000a; Farias and Airoldi, 2000b) and its selection was due to the presence of amine $\left(-\mathrm{NH}_{2}\right)$, which, like the hydroxyl group, is possibly one of the active sites present in chitosan, a solid which was quite effective in PAHs adsorption (Assunção Filho, 2004). The soot formed during acetylene synthesis and the babaçu epicarp are abundant industrial byproducts and their utilization as adsorbents can have reasonable economical viability. The benzoin gum is a resin extracted from plants belonging to the Styracaceae family, so far used as fixer in the cosmetics industry and as precursor of other products in the pharmaceutical industry. Absorbance capacity and low price could represent favorable parameters to determine the use of these solids as adsorbents. 
Nevertheless, the results found showed that a slight variation occurred in the PAHs concentration in the supernatant as a function of time, which indicates that, in this case and under these conditions, these solids seem to be less

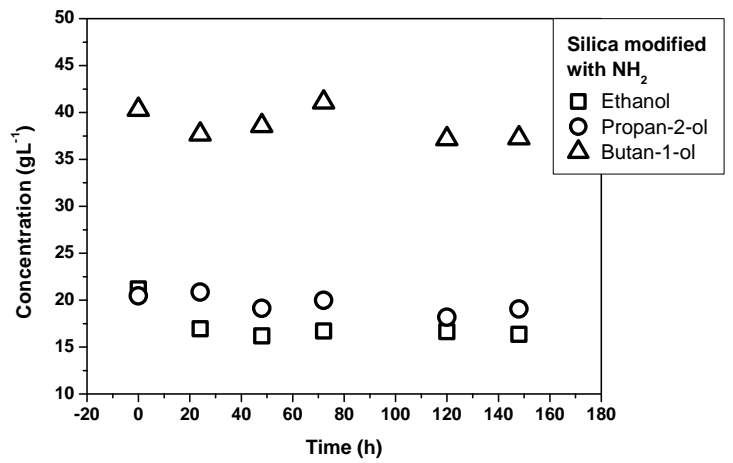

Figure 8. Supernatant concentrations of oil/ethanol, oil/propan-2-ol and oil/butan-1-ol systems as a function of adsorption time over silica modified with $\mathrm{NH}_{2}$, at $350 \mathrm{~nm}$ and $28 \pm 1{ }^{\circ} \mathrm{C}$.

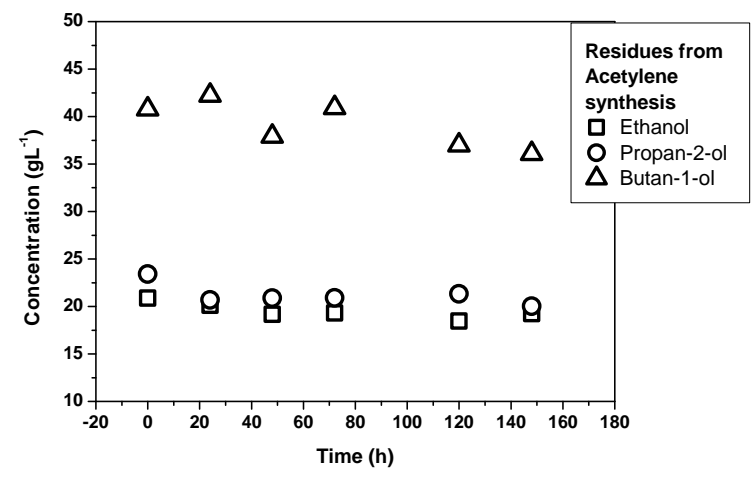

Figure 9. Supernatant concentrations of oil/ethanol, oil/propan-2-ol and oil/butan-1-ol systems as a function of adsorption time over residues from acetylene synthesis, at $350 \mathrm{~nm}$ and $28 \pm 1^{\circ} \mathrm{C}$.

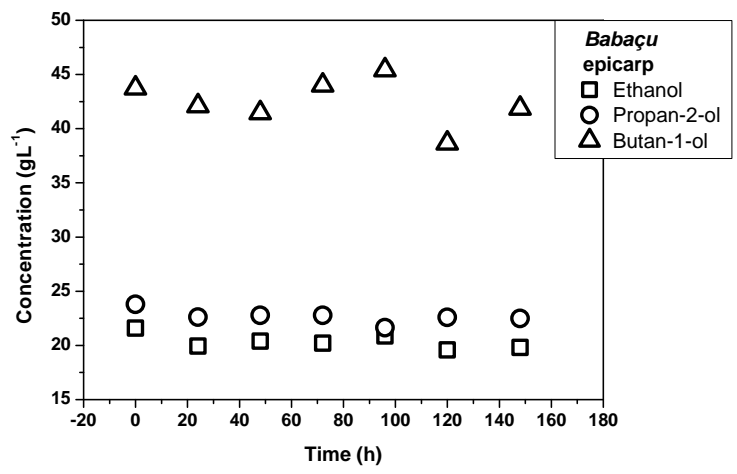

Figure 10. Supernatant concentrations of oil/ethanol, oil/propan-2-ol and oil/butan-1-ol systems as a function of adsorption time over babaçu epicarp, at $350 \mathrm{~nm}$ and $28 \pm 1^{\circ} \mathrm{C}$. appropriate than activated carbon to adsorption operations.

Recovered oils were obtained by solvent evaporation after the adsorption process on solids. In his studies, however, Assunção Filho (2004) obtained high acidity index values at the end of the lubricant oils recovery process. In this article, in order to determine the acidity, two systems, namely the samples of oil/ethanol after adsorption over activated carbon and oil/propan-2-ol after adsorption over silica gel, were put in contact with alumina, a solid with alkaline characteristics that may act as neutralizing agent. The acidity indices of these two systems were determined before and after conducting this procedure (contact with alumina), making possible the calculation of the acidity variation.

These systems were selected because they presented better adsorption results and the neutralizing effects could be extended to other systems. However, tests for the determination of this index showed that the variation rate was only $0.5 \%$ in the oil extracted by ethanol and treated with activated carbon, and $6.7 \%$ in the oil extracted by propan-2-ol and treated with silica gel. After solvent distillation, the recovered base oils still presented rather high acidity indices, compared to the levels established by the procedure ASTM D974 and specified by ANP, as shown in Table 2.

These results indicate that alumina is not recommended for the neutralization step of the global recovery process. A viable alternative for acid number correction would be the process

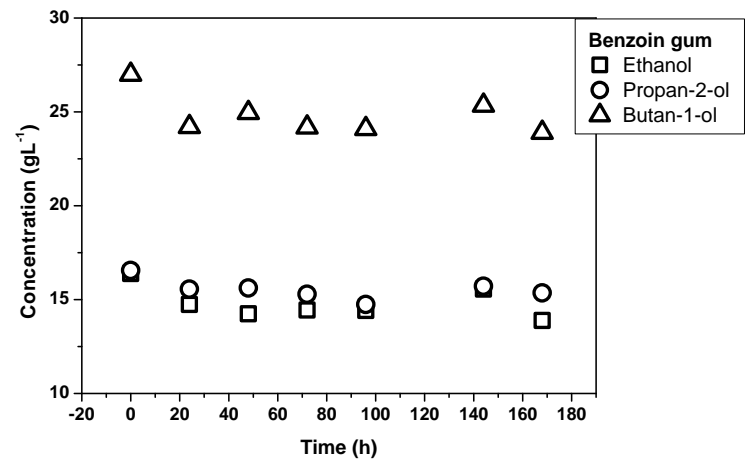

Figure 11. Supernatant concentrations of oil/ethanol, oil/propan-2-ol and oil/butan-1-ol systems as a function of adsorption time over benzoin gum, at 350 $\mathrm{nm}$ and $28 \pm 1{ }^{\circ} \mathrm{C}$. 
Table 2. ASTM and experimental acid numbers of recovered lubricant base oil samples.

\begin{tabular}{lcc}
\hline $\begin{array}{c}\text { Solvent used in base oil } \\
\text { extraction }\end{array}$ & $\begin{array}{c}\text { Acid Number }(\mathrm{mg} \mathrm{KOH} / \mathrm{g}) \\
\text { ASTM (D974) }\end{array}$ & $\begin{array}{c}\text { Acid Number }(\mathrm{mg} \mathrm{KOH} / \mathrm{g}) \\
\text { Experimental }\end{array}$ \\
\hline Ethanol & 0.05 & 6.593 \\
Propan-2-ol & & 2.994 \\
\hline
\end{tabular}

currently employed in the industry, which uses alkaline substances that are able to neutralize undesirable acid compounds found in the oil. However, in general, the process presented here for the recovery of waste lubricant oils showed an improvement on the quality of the final products on various aspects, such as reduction on both viscosity and PAHs content, indicating its potential as an industrial process for the treatment of used oils.

It must be observed, however, that some aspects of the proposed global process of used lubricant oil recovery were not evaluated in this study. The recovery of the adsorbents by desorption of the PAHs, for example, was not investigated and should be considered in further studies with more detail, since this is an important aspect concerning environmental preservation.

\section{CONCLUSIONS}

In this article, a sequence of physical steps (solvent extraction, adsorption on solid surfaces and solvent distillation) was presented aiming to reestablish the main properties of base oils, with a focus on the stage of removal of PAHs by adsorption on different solid surfaces that are commonly used as adsorbents of PAHs, such as activated carbon and silica (in this case, silica modified with $\mathrm{NH}_{2}$ ), and other alternative solids, such as rice husk, residues from acetylene synthesis, babaçu epicarp and benzoin gum. These alternative solids, however, did not provide a high capacity to concentrate PAHs on their surface when compared with the classical adsorbents investigated.

Butan-1-ol presented better efficacy as extraction agent of base lubricant oils, followed by propan-2-ol and ethanol. The methodology for quantifying the PAHs yielded good results, allowing the determination of the PAHs mass variation in the solutions with various solvents by means of calibration curves obtained with toluene.

The adsorption isotherms indicated that activated carbon has a great potential for concentrating PAHs molecules on its surface and, hence, can be used in industrial applications with that purpose. The best system for PAHs concentration comprised activated carbon and ethanol. The recovered oils presented high acid number and solid alumina was not efficient in the correction of this index.

Based upon these results, three main different steps can be viewed as possibly feasible for the recovery process of used lubricant oils: (a) extraction with solvent, (b) adsorption over solids and (c) solvent distillation. Nonetheless, further studies are still required for the improvement of the global process.

\section{REFERENCES}

Ahmedna, M.; Marshall, W. E.; Rao, R. M. Production of granular activated carbons from select agricultural by-products and evaluation of their physical, chemical and adsorption properties. Bioresource Technology, v. 71, p. 113123, 2000. doi:10.1016/S0960-8524(99)00070-X

Ajmal, M.; Rao, R.A.K.; Anwar, S.; Ahmad, J.; Ahmad, R. Adsorption studies on rice husk: removal and recovery of $\mathrm{Cd}(\mathrm{II})$ from wastewater. Bioresource Technology, v. 86, p. 147149, 2003. doi:10.1016/S0960-8524(02)00159-1

Al-Ghouti, M.A.; Al-Atoum, L. Virgin and recycled engine oil differentiation: A spectroscopic study. Journal of Environmental Management, v. 90, p. 187-195, 2007. doi:10.1016/i.jenvman.2007.08.018

Araújo, R. S.; Azevedo, D. C. S.; Cavalcante Jr., C. L.; Jiménez-López, A.; Rodríguez-Castellón, E. Adsorption of polycyclic aromatic hydrocarbons (PAHs) from isooctane solutions by mesoporous 
molecular sieves: Influence of the surface acidity. Microporous and Mesoporous Materials, v. 108, p. 213-222, 2008. doi:10.1016/i.micromeso.2007.04.005

Assunção Filho, J. L. Processo de recuperação de óleos lubrificantes básicos, através da adsorção de HPAs sobre sólidos de diferentes naturezas. Dissertação de Mestrado. Programa de PósGraduação em Química, Universidade Federal do Maranhão, 2004. (in Portuguese).

Brüggemann, O.; Freitag, R. Determination of polycyclic aromatic hydrocarbons in soil samples by micellar electrokinetic capillary chromatography with photodiode-array detection. Journal of chromatography A, v. 717, p. 309-324, 1995 . doi:10.1016/00219673(95)00536-X

Chang, C.-L.; Fogler, H. S. Asphaltene stabilization in alkyl solvents using oil-soluble amphiphiles, In: SPE International Symposium on Oilfield Chemistry, Society of Petroleum Engineers, 1993, p. 339-345. doi:10.2118/25185-MS

CONAMA. Resolução Nº 9, 31 de agosto de 1993. Dispõe sobre óleos lubrificantes e atividades de gerenciamento correspondentes. Conselho Nacional do Meio Ambiente, 1993. Available at: http://www.mma.gov.br/port/conama/res/res9 3/res0993.html. Accessed on: 10/08/2010. (in Portuguese).

Dubey, S. T., Waxman, M. H. Asphaltene adsorption and desorption from mineral surfaces. SPE Reservoir Engineering, v. 6, p.389-395, 1991. doi:10.2118/18462-PA

Espada, J. J.; Coto, B.; van Grieken, R.; Moreno, J. M. Simulation of pilot-plant extraction experiments to reduce the aromatic content from lubricating oils. Chemical Engineering and Processing, v. 47, p. 1398-1403, 2008. doi:10.1016/j.cep.2007.06.012

Farias, R. F.; Airoldi, C. Mechanically induced structural modifications in metal-doped lamellar silica. Journal of Non-Crystalline Solids, v. 261, p. 181-185, 2000a. doi:10.1016/500223093(99)00595-5

Farias, R. F.; Airoldi, C. Thermochemical features of lamellar silica, copper, nickel and cobalt-doped forms synthesized from neutral amine route. Colloids and Surfaces A: Physicochemical and Engineering Aspects, v. 172, p. 145-152, 2000b. doi:10.1016/S0927-7757(00)00577-X

Gómez-Rico, M.F.; Martín-Gullón, I.; Fullana, A.; Conesa, J.A.; Font, R. Pyrolysis and combustion kinetics and emissions of waste lube oils. Journal of Analytical and Applied Pyrolysis, v. 68-69, p. 527-546, 2003. doi:10.1016/S0165$\underline{2370(03) 00030-5}$

Grieken, R.; Coto, B.; Peña, J.L.; Espada, J.J. Application of a generalized model to the estimation of physical properties and description of the aromatic extraction from a highly paraffinic lubricating oil. Chemical Engineering Science, v. 63, p. 711-720, 2008. doi:10.1016/i.ces.2007.10.013

Hamad, A.; Al-Zubaidy, E.; Fayed, M. E. Used lubricating oil recycling using hydrocarbon solvents. Journal of Environmental Management, v. 74, p. 153-159, 2005. doi:10.1016/i.jenvman.2004.09.002

Jiao, X. C.; Xu, F.L.; Dawson, R.; Chen, S. H.; Tao, S. Adsorption and absorption of polycyclic aromatic hydrocarbons to rice roots. Environmental Pollution, p. 148 , v. 230-235, 2007.

László, K.; Bóta, A.; Nagy, L. G. Characterization of activated carbons from waste materials by adsorption from aqueous solutions. Carbon, v. 35 , p. 593-598, 1997. doi:10.1016/S00086223(97)00005-5

Mousavi-Dehghani, S. A.; Riazi, M. R.; Vafaie-Sefti, M.; Mansoori, G. A. An analysis of methods for determination of onsets of asphaltene phase separations. Journal of Petroleum Science and Engineering, v. 42, p. 145-156, 2004. doi:10.1016/j.petrol.2003.12.007

Myers, D. Surfaces, interfaces, and colloids principles and applications, New York: WileyVCH, 1999. doi:10.1002/0471234990

Priyanto, S.; Mansoori, G. A.; Suwono, A. Measurement of property relationships of nanostructure micelles and coacervates of asphaltene in a pure solvent. Chemical 
Engineering Science, v. 56, p. 6933-6939, 2001. doi:10.1016/S0009-2509(01)00337-2

Raadnui, S.; Kleesuwan, S. Low-cost condition monitoring sensor for used oil analysis. Wear, $\mathrm{v}$. 259, p. 1502-1506, 2005. doi:10.1016/i.wear.2004.11.009

Ramasamy, K. K.; T-Raissi, A. Hydrogen production from used lubricating oils. Catalysis Today, v. 129, p. 365-371, 2007. doi:10.1016/i.cattod.2006.09.037

Ramos, A. C. S.; Haraguchi, L.; Notrispe, F. R.; Loh, W.; Mohamed, R. S. Interfacial and colloidal behavior of asphaltenes obtained from Brazilian crude oils. Journal of Petroleum Science and Engineering, v. 32, p. 201-216, 2001. doi:10.1016/S0920-4105(01)00162-0

Rauckyte, T.; Hargreaves, D. J.; Pawlak, Z. Determination of heavy metals and volatile aromatic compounds in used engine oils and sludges. Fuel, v. 85, p. 481-485, 2006. doi:10.1016/i.fuel.2005.08.004

Rincón, J.; Cañizares, P.; García, M. T. Regeneration of used lubricant oil by ethane extraction. The Journal of Supercritical Fluids, v. 39, p. 315-322, 2007. doi:10.1016/i.supflu.2006.03.007

Santos, J. C. O.; dos Santos, I. M. G.; Souza, A. G.; Sobrinho, E. V.; Fernandes Jr., V. J.; Silva, A. J. N. Thermoanalytical and rheological characterization of automotive mineral lubricants after thermal degradation. Fuel, v. 83, p. 2393-2399, 2004. doi:10.1016/i.fuel.2004.06.016

Sarrade, S.; Schrive, L.; Gourgouillon, D.; Rios, G. M. Enhanced filtration of organic viscous liquids by supercritical $\mathrm{CO} 2$ addition and fluidification. Application to used oil regeneration. Separation and Purification Technology, v. 25, p. 315-321, 2001. doi:10.1016/S1383-5866(01)00058-2

Serrano, D. P.; Aguado, J.; Escola, J. M.; Garagorri, E. Performance of a continuous screw kiln reactor for the thermal and catalytic conversion of polyethylene-lubricating oil base mixtures. Applied Catalysis B: Environmental, v. 44, p. 95105, 2003. doi:10.1016/\$0926-3373(03)00024-9

Shaw, D. J. Introdução à química dos colóides e de superfícies. São Paulo: Edgard Blücher, 1975. (in Portuguese).

Shishkin, Y.L. A new quick method of determining the group hydrocarbon composition of crude oils and oil heavy residues based on their oxidative distillation (cracking) as monitored by differential scanning calorimetry and thermogravimetry. Thermochimica Acta, v. 440, p. 156-165, 2006. doi:10.1016/j.tca.2005.11.008

Shreve, R. N.; Brink Jr., J. A. Indústrias de processos químicos. Rio de Janeiro: Guanabara Koogan S.A., 1997. (in Portuguese).

Silvestein, R. M.; Webster, F. X. Spectrometric identification of organic compounds. New York: John Wiley and Sons, 1997.

Uçar, S.; Karagöz, S.; Yanik, J.; Saglam, M.; Yuksel, M. Copyrolysis of scrap tires with waste lubricant oil. Fuel Processing Technology, v. 87, p. 53-58, 2005. doi:10.1016/i.fuproc.2005.06.001 